\title{
Body Posture Analysis and Ergonomic Risk Assessment on Container Crane Operators
}

\author{
Mufatihatul Aziza Nisa*, Gusti Firdha Amalia** \\ * Department of Occupational Health and Safety, School of Public Health Faculty of Medicine Lambung Mangkurat University, \\ mufatihatul.nisa@ulm.ac.id \\ *** Occupational Health and Safety, Study Center of Occupational Health and Safety Lambung Mangkurat University
}

DOI: 10.29322/IJSRP.11.12.2021.p12073

http://dx.doi.org/10.29322/IJSRP.11.12.2021.p12073

\begin{abstract}
Most of the operational activities of loading and unloading in container terminal facility for domestic and international customers in the area of East Indonesia, utilize hoisting apparatus, such as container crane. While it works, the crane operator will look down and the back muscle will hold body weight partially. If the activity done repeatedly, there is a risk of Cumulative Trauma Disorders (CTDs), also known as Musculoskeletal Disorders, repetitive motion injury, repetitive stress injury, or occupational fatigue syndrome. The aim of this study to analyze body posture and assess the ergonomic risk of container crane operators. The study used descriptive observational design by assessing the posture using REBA Method, interview and discussion at container terminal facility for domestic and international customers in Indonesia by August of 2016 with 2 crane operators as samples for the study. The result of body posture risk assessment using REBA shows the body parts that had high score are trunk, neck, upper arms and forearms. However, the high score is more dominant for the first respondent that was not using seatbelt. The efforts to control the risk can be done by using monitoring application, conducting health campaigns and educating the workers with the aim to decrease the risk caused by unnatural body posture.
\end{abstract}

Index Terms- Body posture, Container crane, Operators, REBA

\section{INTRODUCTION}

$\mathrm{T}$ The container terminal facility providing most of the operational activities of loading and unloading in utilize hoisting apparatus. One of the hoisting apparatus operations is container crane. The container crane operator runs the hoisting apparatus from the inside of a cabin through hand-operated joystick. Container crane operator works for 4 hours and the target is to load and unload as much as 20 to 30 boxes of container per hour [1].

The improvement in mechanization and automation is directly proportional to work speed and productivity increase, but it can cause a work become monotone and the work posture that does not change much also repetitive over a long time [2]. During work, the crane operator will look down while the back muscle will hold body weight partially. The other body part that has heavy weight is the neck that supports the head while the body position bows [3].

While bowing, the backbone will move to the front side and the body will strain. The work posture is an unnatural work posture [4]. If the activity done repeatedly then, the risk that will arise is the presence of the disorder's signs and symptoms, such as Cumulative Trauma Disorders (CTDs). CTDs is the term used to describe the soft tissue injury and trauma, including muscles, tendons, ligaments, joints, cartilages, and central nervous system [5]. This matter also known as Musculoskeletal Disorders, repetitive motion injury, repetitive stress injury, or occupational fatigue syndrome [6].

The data from container terminal facility shows that myalgia complaints (muscle pain and sore) also low back pain complaints on the crane other apparatus operators became one of the most disease complaints in 2013 and 2014, so it can be concluded that CTDs symptom has started to become a serious problem. Considering the potential impact of health risk in the future, therefore, an effort must be done to assess the risk and to improve the work posture of container crane operators by taking pictures of their work posture, then conducting a measurement and calculation their angle based on REBA (Rapid Entire Body Assessment) method.

\section{METHODOLOGY}

This study used descriptive observational design by assessing the posture of container crane operators using REBA (Rapid Entire Body Assessment) method. REBA application helped to determine the indication of risk level and important condition, also to determine whether action is necessary to take or not [7]. Then, the analysis result of REBA will be re-analyzed based on the supporting literature and the result of interviewing the container crane operators. The sample is 2 crane operators. The study was done at the container terminal facility in Indonesia by August of 2016. 


\section{RESULT}

\section{A. The REBA Measurement Result of Group A}

The measurement result of Group A was Trunk, Neck, Leg. The measurement result of the trunk and neck of the first respondent is $40^{\circ}$ and the posture score is 3 (high). The neck condition is bowing in $45^{\circ}$ angle and twisted, resulting in +1 point. The measurement result of the leg angle shows that only one of the legs of first respondent is well grounded. The score result in the risk classification is high. The measurement result of trunk angle of the second respondent is $20^{\circ}$ and the posture score is 2 (medium). The neck condition is bowing in $40^{\circ}$ and twisted, resulting in +1 point. Meanwhile, both of the leg posture of the second respondent is well grounded. The score result in the risk classification is medium.

The twisted neck of both of the respondents added +1 points in the REBA scoring, which, according to NIOSH (2014), both of these conditions are unnatural [8]. The unnatural or extreme body posture is easy to describe as an abnormal body posture and not efficient for the human body anatomy [4]. The first respondent had their only left leg that well-grounded on the footrest and their left leg was hanged, therefore, the score for the leg is high. The second respondent had their leg posture well-grounded on the footrest with flexion angle more than $150^{\circ}$. According Tarwaka (2015), the leg posture of the respondent while they sitting with more than $150^{\circ}$ described as well supported as the standing posture [9].

The measurement result of Group A (Trunk, Neck, Leg) is presented in Table 1 below.

Table 1. The REBA Measurement Result of Group A (Trunk, Neck, Leg)

\begin{tabular}{llllll}
\hline \multirow{2}{*}{ Respondent } & Group A & Score & Neck & Score & Leg \\
\cline { 2 - 6 } 1 & Trunk & 3 & $45^{\circ}$ & 3 & $\begin{array}{l}\text { One of the legs is well } \\
\text { grounded }\end{array}$ \\
\hline 2 & $40^{\circ}$ & 3 & $40^{\circ}$ & 2 & $\begin{array}{l}\text { Both of the legs are well } \\
\text { grounded }\end{array}$ \\
\hline
\end{tabular}

\section{B. The REBA Measurement Result of Group B}

Group B is divided into 3 categories, which are upper arm, forearm and wrist. The measurement result of both of the upper arm's angles of the first respondent is a flexion angle between $45^{\circ}-90^{\circ}$ with the score of 3 , and the position of right upper arm is away from the abduction, resulting in +1 point with the classification of risk level is high. The measurement result of right upper arm of the second respondent is a flexion angle in the amount of $115^{\circ}$ in the range $>90^{\circ}$ with the score of 4 (very high), the classification of risk level is medium. Meanwhile, the angle of left upper arm is $85^{\circ}$ in the range of $60^{\circ}-100^{\circ}$ with the score of 3 (high), the classification of risk level is medium.

The measurement result of both of the forearm's angles of the first respondent is a flexion angle in the range of $>60^{\circ}-100^{\circ}$ with the score of 2 and the risk level is medium. The measurement result of both of the forearm's angle of the second respondent is $60^{\circ}-100^{\circ}$ with the score of 1 and the risk level is low. The measurement result of right wrist's angle of the first respondent is a flexion angle of the hand that held the joystick in the amount of $0^{\circ}-15^{\circ}$ with the score of 1 (low). Meanwhile, the left wrist's angle is the extension of $>15^{\circ}$ with the score of 2 (medium). The measurement result of both of the wrist's angles of the second respondent is a flexion angle of the hand that held the joystick in the amount of $0^{\circ}-15^{\circ}$ with the score of 1 (low) and the score result is 2 (medium).

The position of shoulder and upper arms, both left and right, of the container crane operator, especially the ones without using seatbelt, was found experiencing flexion in the range of $45^{\circ}-90^{\circ}$ away from the abduction. According to NIOSH (2014), the posture is also unnatural [8]. The shoulder position of the operator that did not use seatbelt is found away from the abduction, and the shoulder position of the operator that used seatbelt tend to neutral. During the observation, the shoulder position of the operator that used seatbelt was not moving away from the abduction. The difference happened due to the operator used their seatbelt, which can decrease their weight load in the amount of $79 \%$, which will cause the body and the shoulder position supported and back to the abduction [3]. The first respondent had medium risk level due to the existence of flexion angle in the amount of $>60^{\circ}-100^{\circ}$ in the forearm. Meanwhile, the forearm angle of the second respondent is a flexion angle in the both of their hands, in the amount of $60^{\circ}-100^{\circ}$. The difference affected by the utilize of seatbelt during work, which can decrease the load of Trapezius muscle, neck muscle and body weight, also improve relax feeling in the arm muscle [3].

Unnatural posture was found in the wrist, it was quite stand out for the first respondent, their left wrist extended more than $15^{\circ}$, meanwhile there is flexion in the amount of $0^{\circ}-15^{\circ}$ on the right side. The wrist posture of second respondent tend to stable with the flexion angle less than $15^{\circ}$ on both sides. L. Pigini, et al mentioned that beside the seatbelt, horizontal armrest also helps to decrease the work of Trapezius muscle as much as $67 \%$ and lumbar muscle as much as $64 \%$. The potential of unnatural posture of the first respondent correlates with their unsupported work posture by the seatbelt, added with there is no horizontal armrest, therefore, their back up to their shoulder and arm will tense up and have to maintain stable body position [3]. 
Table 2. The REBA Measurement Result of Group B

\begin{tabular}{llllll}
\hline Respondent & Group B & Right & Score & Left & Score \\
\hline \multirow{2}{*}{1} & Upper arm & $50^{\circ}$ & 4 & $80^{\circ}$ & 4 \\
\cline { 2 - 6 } & Forearm & $115^{\circ}$ & 2 & $98^{\circ}$ & 2 \\
\cline { 2 - 6 } 2 & Wrist & $15^{\circ}$ & 1 & $>20^{\circ}$ & 3 \\
\hline \multirow{2}{*}{ Upper arm } & $110^{\circ}$ & 4 & $85^{\circ}$ & 1 \\
\cline { 2 - 5 } & Forearm & $60^{\circ}$ & 1 & $>60^{\circ}$ & 1 \\
\cline { 2 - 5 } & Wrist & $<15^{\circ}$ & 1 & $<15^{\circ}$ & 2 \\
\hline
\end{tabular}

\section{The REBA Measurement Result of Load, Coupling and Activity}

Based on the observation result of the first and second respondent, it was found that the load was happening during the operator moved the joystick by their right and left hand to move the spreader up and down (with the weight of $<5 \mathrm{~kg}$ ), the score is 0 . The coupling score of the joystick movement by their hands is 0 . The work activity of moving the container using joystick repeatedly caused the body and neck activity of bowing statically for more than one minute, also the unstable base caused by the movement of cabin forward and backward during container movement that also causing vibration, the score is 2 .

The activity of the operators is risky for their body and body posture [9]. The identified activity is the work of moving the container by using hand-operated joystick repeatedly, the act of bowing body and neck statically for more than one minute also unstable base due to the forward and backward cabin movement during moving the container, it also caused vibration.

Table 3. The REBA Measurement Result of Load, Coupling and Activity

\begin{tabular}{|c|c|c|c|c|c|c|}
\hline \multirow{2}{*}{ Respondent } & \multicolumn{6}{|c|}{ Load, Coupling and Activity } \\
\hline & Load & Score & Coupling & Score & Activity & Score \\
\hline 1 & $<5 \mathrm{~kg}$ & 0 & Good & 0 & $\begin{array}{l}\text { The body and neck bow statically for } \\
\text { more than } 1 \text { minute. The unstable base } \\
\text { causing vibration }\end{array}$ & 2 \\
\hline 2 & $<5 \mathrm{~kg}$ & 0 & Good & 0 & $\begin{array}{l}\text { The body and neck bow statically for } \\
\text { more than } 1 \text { minute. The unstable base } \\
\text { causing vibration }\end{array}$ & 2 \\
\hline
\end{tabular}

\section{The REBA Score Result and Risk Assessment Matrix}

There are differences of REBA final scores of the both of container crane operators of PT. X, the scoring and the risk level. The REBA score of the first respondent is 11, which, according to Tarwaka (2015) is very high [9]. Meanwhile, the second respondent's score is 6 , which is lower than the first respondent and the risk level is medium. Based on the description, the medium risk level described as all activities and control measures must be done before the work continues.

Table 4. The REBA Score Result

\begin{tabular}{lll}
\hline Respondent & REBA Scoring Result & Risk Level \\
\hline 1 & 11 & High \\
\hline 2 & 6 & Medium \\
\hline
\end{tabular}

The risk assessment matrix above shows that the ergonomic risk of the loading and unloading activity that was done by the container crane operators is medium. If the risk correlates with the health impact, it will be shown in the health data of the container crane operators that complaint frequently regarding musculoskeletal pains they felt. The risk assessment by risk matrix shows that the risk level is medium. The postural assessment of the unnatural body posture is high for the respondent that was not using seatbelt. While bowing, the backbone moves to the front side, therefore, the body will experience pressure and load hoarding in certain body parts. The operators will experience musculoskeletal complaints, such as back pain, neck pain or low back pain. Musculoskeletal is the pain on the skeletal muscle felt by a person, ranges from mild up to very painful. 
When unnatural posture is out of control of the muscle to move back to its return place and function, it can cause a domino effect to the body posture. The condition will induce the pain on certain body parts [4]. One of the unnatural work posture risks found within the container crane operators can cause health risks, such as Cumulative Trauma Disorders. CTDs itself affecting the upper body parts, focusing back side and arm side more than other parts of human anatomy [10]. Pain complaints on certain body parts and low back pain complaints are early indicators of CTDs, specifically, will cause Musculoskeletal Disorders (MSDs). MSDs is one of the disorder correlates with muscles, tendons, ligaments, nervous system, bone structures and blood vessels.

\section{CONCLUSION}

The result of body posture risk assessment using REBA shows the body parts that had high score are trunk, neck, upper arms and forearms. However, the high score is more dominant for the first respondent that was not using seatbelt. The efforts to control the risk can be done based on the control hierarchy, which are technical control by using monitoring application as a visualization that connects with the camera installed below the cabin, conducting health campaigns through poster and educating the workers with the aim to decrease the risk caused by unnatural body posture.

\section{ACKNOWLEDGMENT}

We would like to thank to all the roles involved, respondents, research sites, and research assistants. .

\section{REFERENCES}

[1] Nuna. Analisa Keluhan Musculoskeletal Disorder Operator Container Crane di PT. Terminal Petikemas Surabaya, Universitas Airlangga, 2015.

[2] Tarwaka, Ergonomi Industri: Dasar-Dasar Pengetahuan Ergonomi dan Aplikasi di Tempat Kerja, Surakarta: Harapan Press, 2015.

[3] L. Pigini D., et al., Ergonomics solutions in designing workstations for operators cranes on harbours, 2006.

[4] Parker K.G., and Imbus H.R., Cumulative Trauma Disorders: Current Issues and Ergonomic Solutions: A System Approach, Boca Raton: Lewis Publishers, 1992.

[5] Daugherty J.E., Industrial Safety Management: A Practical Approach, Rockville: Government Institutes, Inc., 1999.

[6] Putz-Anderson V., Cumulative Trauma Disorders: A Manual for Musculoskeletal Diseases of the Upper Limbs, Bristol: Taylor \& Francis, 1988.

[7] McAtarnney L., and Corlett E.N., Rule a Survey Method for the Investigation of Work-Related Musculoskeletal Disorders, Applied Ergonomics, vol. 24 no. 2, p. 91-99, 1993.

[8] NIOSH, Observation-Based Posture Assessment: Review of Current Practice and Recommendations for Improvement, Department of Health and Human Services: Center for Disease Control and Prevention, 2014.

[9] Tarwaka, Keselamatan, Kesehatan Kerja dan Ergonomi (K3E) dalam Perspektif Bisnis, Surakarta: Harapan Press, 2015.

[10] Tayyari F., and Smith J.L., Occupational Ergonomics: Principles and Applications. New York: Chapman \& Hall, 1997.

[11] for publication)," IEEE J. Quantum Electron., submitted for publication.

\section{AUTHORS}

First Author - Mufatihatul Aziza Nisa, Department of Occupational Health and Safety, School of Public Health Faculty of Medicine Lambung Mangkurat University, mufatihatul.nisa@ulm.ac.id

Second Author - Gusti Firdha Amalia, Occupational Health and Safety, Study Center of Occupational Health and Safety Lambung Mangkurat University, gustifirdha@gmail.com

Correspondence Author - Mufatihatul Aziza Nisa, Department of Occupational Health and Safety, School of Public Health Faculty of Medicine Lambung Mangkurat University, mufatihatul.nisa@ulm.ac.id 